\title{
st \\ Demonstração do movimento da luz no ensaio de óptica de Descartes
}

\author{
José Portugal dos Santos Ramos
}

A opção pela tradução aqui apresentada dos Discursos I, II, III, IV e viII de $A$ dióptrica decorre da sistematização que os mesmos conferem à obra de Descartes. ${ }^{1}$ No ano de ${ }_{163} 7$ foi editada em Leyde, por Jan Maire, uma coleção em língua francesa de quatro obras inéditas - dentre as quais se encontrava $A$ dióptrica - de um autor anônimo, residente na Holanda desde meados da década de 1620 (cf. AT, 6, p. v-vI). ${ }^{2}$ A Dióptrica, portanto, foi um dos três ensaios científicos que Descartes publicou juntamente com o Discurso do método. Esse ensaio é um tratado de óptica, compreendendo principalmente uma teoria da refração da luz que estabelece, pela primeira vez, a lei do seno, além de conter um estudo sobre novos instrumentos ópticos (cf. Koyré, 1992, p. 11). Ela é composta por dez Discursos (capítulos) com a seguinte ordenação: (1) da luz, (2) da refração, (3) do olho, (4) dos sentidos em geral, (5) das imagens formadas no fundo do olho, (6) da visão, (7) dos meios para aperfeiçoar a visão, (8) as formas dos corpos transparentes que refratam a luz, (9) a descrição das lunetas e, por fim, (10) a metodologia para a elaboração de lentes.

Essa obra de Descartes é constituída por três grandes campos teóricos. No início de A dióptrica, Descartes demarca os campos teóricos na seguinte ordem de investigação:

“[...] Começarei pela explicação do movimento da luz e de seus raios luminosos; depois, tendo feito uma breve descrição das partes do olho, eu darei detalhadamente de que modo se faz a visão; e, em seguida, após ter anotado todas as coisas

1 Utilizei para a tradução a edição de $A$ dióptrica que se encontra no volume 6 das Oeuvres de Descartes, editadas por Charles Adam e Paul Tannery.

2 Shea (1997) sustenta que $A$ dióptrica deveria ser estudada em conjunto com o Discurso do método, pois esse era o intuito de Descartes. Acrescenta-se a esses dados que as ilustrações de $A$ dióptrica foram desenhadas por Franz van Schooten (cf, AT, 6, p. v-vI). 
que são capazes de torná-la mais perfeita, mostrarei como podem ser ajudadas pelas invenções que descreverei."(AT, $6,82-3) .^{3}$

Os conteúdos desses campos teóricos articulam-se na sistematização da ciência óptica de Descartes, mediante a aplicação instrumental de sua matemática universal e pelo uso de analogias e hipóteses. O primeiro campo teórico descreve as demonstrações das leis de incidência e refração da luz. Esse campo teórico é estabelecido nos Discursos i e II. O segundo campo teórico descreve a instrumentalização da matemática por meio de exames fisiológicos. Esse campo teórico é estabelecido nos Discursos III, IV, v e vi da obra. Por fim, o terceiro campo descreve a elaboração e a manipulação de instrumentos ópticos e é descrito nos Discursos viı, viıı, Ix e x da obra.

Os Discursos I e ir de $A$ dióptrica expõem os fatores que viabilizam à ciência de Descartes examinar o objeto de estudo óptico. Nesses dois discursos, Descartes relata

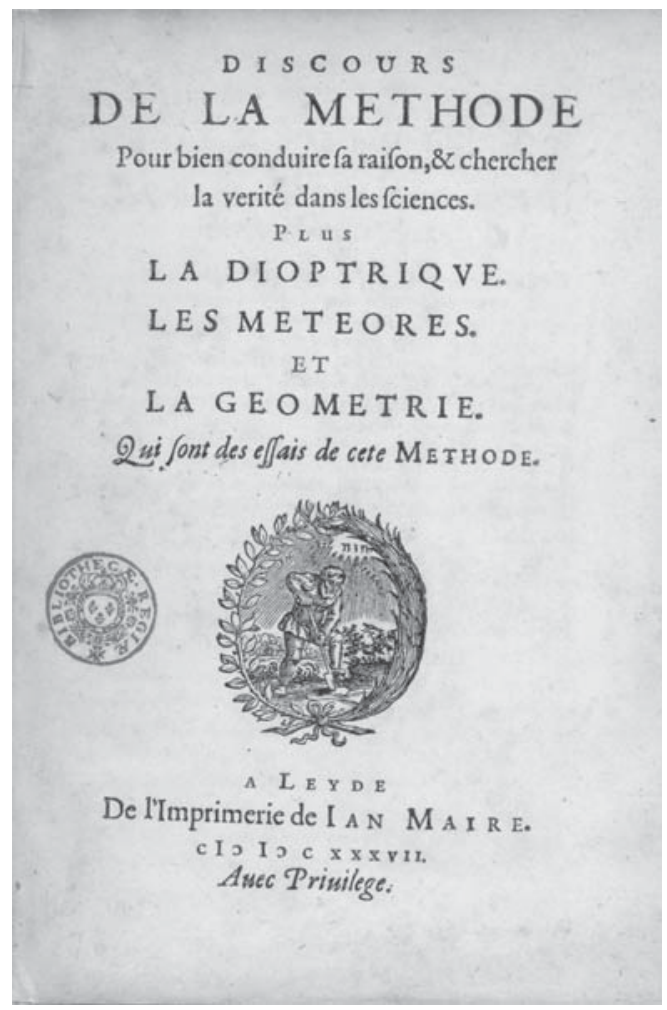
que a natureza da luz não é passível de descrição metódica. Nessa perspectiva é que Descartes compreende que essa explicação torna-se impertinente, na medida em que não se propõe realizar a investigação acerca da natureza mesma do objeto, mas apenas tratar do modo como é possível descrever a ação da luz mediante a explicação mecânica do movimento. A estratégia de Descartes consiste, assim, em fazer uso de hipóteses e analogias, revelando seu caráter determinante para o empreendimento científico.

Pela analogia do movimento da bengala, utilizada por um cego para perceber os objetos a sua volta, Descartes dese-

Figura 1. Página título da edição original de ${ }^{163} 7$ do Discurso do método, na qual este é uma espécie de apresentação geral, que é exemplificada depois por três ensaios do método, iniciando por $A$ dióptrica.

3 Segundo Cottingham: "O uso de analogias, tais como a da bengala e a da fermentação das uvas, fazem parte do mecanismo que Descartes utiliza para explicar a propagação da luz. Há que se dizer que, a despeito da feição empírica das analogias cientificas de Descartes, encontraremos muita pouca investigação empírica, isto é, no sentido moderno do termo, a fundamentar suas alegações de que os fenômenos da luz [...] se dão realmente de maneira análoga àquela dos modelos invocados “ (Cottingham, 1993, p. 19). 
ja tornar inteligível o modo pelo qual a luz pode ser considerada um movimento ou uma ação a qual, através de um medium, parte do corpo luminoso e chega aos olhos de um observador. Por meio da analogia do barril - recipiente preenchido de uvas pisadas e com vários orifícios -, cujo conteúdo Descartes compara à matéria sutil que supostamente preencheria os espaços outrora considerados vazios, ele pretende explicar como a luz pode ser considerada a ação pela qual as partes mais altas dessa matéria tendem para baixo como se fosse em linha reta. Com a analogia do jogo de raquete, Descartes pretende comparar o raio luminoso à bola rebatida com força pela força pela raquete. Assim, Descartes concebe a ação da luz por meio das mesmas leis do movimento mecânico.

No Discurso iı da Dióptrica, Descartes aplica sua perspectiva matemática na descrição dos processos fisiológicos do olho. Nesse discurso, Descartes demonstra o modo como a refração ocorre no interior do olho e explica como o olho se move. Essa explicação para o movimento fisiológico do olho pretende fornecer uma descrição minuciosa dos mecanismos da percepção sensorial e sua possível relação com as informações decodificadas no cérebro. Esse aspecto da ciência óptica de Descartes é relevante, porque permite dissociar suas concepções filosóficas daquelas expostas nos manuais escolásticos do século xvi. Isso porque, para Descartes, é necessário ter o cuidado de não supor, como pareciam fazer os filósofos da Escola, que, para ter consciência sensorial, a alma precisa inspecionar certas imagens transmitidas ao cérebro por objetos empíricos (cf. AT, 6, p. 112). Em Descartes, a explicação do movimento fisiológico do corpo é regida por uma concepção mecanicista. Acrescente-se que, nessa concepção de movimento, deve-se excluir dos processos fisiológicos todas as qualidades ocultas.

No Discurso iv de $A$ dióptrica, Descartes versa sobre os sentidos em geral, antes de tratar especificamente da visão. Ao longo deste discurso, Descartes demonstra como todos os objetos empíricos são decodificados através do agente da observação. Isso ocorre apenas porque tais objetos movem-se, por meio do movimento local dos corpos, através dos corpos transparentes que estão entre esses objetos e o observador (cf. AT, 6, p. 13o-1). Sendo, pois, do âmbito fisiológico essa explicação, Descartes relata que os nervos ópticos, que estão ligados ao cérebro, movem-se de diversas maneiras; e, desse modo, possibilitam na mesma medida ao observador visualizar o objeto de modo diversificado. Com isso, para Descartes, a ação de visualizar o objeto não está ligada apenas ao movimento que ocorre no interior dos olhos, mas também ao que se passa no interior das estruturas do cérebro.

No Discurso viıI da obra, Descartes descreve as figuras que devem possuir os corpos transparentes que servem para desviar os raios pela refração. Revela, então, sua preferência pela utilização das formas ovais, utilizando a inteligibilidade da elipse e da hipérbole, para demonstrar que é possível fazer construções físicas que estejam previamente informadas pela inteligibilidade matemática da lei da refração. 


\section{Os primeiros interesses de Descartes por óptica}

Embora $A$ dióptrica tenha sido publicada em ${ }_{1637}$, sabe-se que, desde o tempo de juventude, Descartes investigava questões de óptica, sobretudo no que dizia respeito aos problemas de ilusão óptica. Em alguns dos fragmentos de juventude, recorda uma série de possíveis ilusões de óptica, descrevendo como, em um jardim, as sombras podem representar diversas figuras, dependendo de como os raios solares reflitam por entre a folhagem das copas das árvores; do mesmo modo, em um quarto escuro, onde a luz penetra por pequenas fendas, pode-se obter línguas de fogo e outras figuras no ar mediante o uso de espelhos.

Nos Excerpta mathematica, por exemplo, há diversas referências a problemas de óptica. ${ }^{4}$ Outro exemplo do interesse de Descartes por questões de óptica é a referência que o jovem francês faz, no De solidorum elementis (Os exercícios sobre os elementos sólidos), a respeito da possibilidade de mensuração da luz. Assim, na segunda parte dessa obra, Descartes assinala que

a melhor de todas as maneiras para formar os sólidos consiste em colocar um Gnomo (um instrumento composto de uma estaca perpendicular ao horizonte) de maneira posta em um ângulo vazio dentro de todos os casos dados; e, assim, considerar que a figura inteira pode ser resolvida pelo cálculo dos triângulos (AT, 10, p. 269).

Finalmente, nos escritos de juventude, destaca-se, sobretudo, a Regra viıI das Regulae ad directionem ingenii, na qual Descartes assinala a diferença que há entre a concepção matemática dos ângulos de incidência e refração e a demonstração física da anaclástica (cf. AT, 10, p. 393-4).

Há outras fontes de investigação dos primeiros escritos de $A$ dióptrica, a saber, as possíveis influências de pesquisas dos antecessores de Descartes e a correspondência que o filósofo francês manteve com alguns interlocutores da época. Dentre as possíveis influências que Descartes teve para dedicar-se à óptica encontram-se principalmente os manuais das escolas e as notícias das pesquisas científicas de Galileu, Tycho Brahe e Kepler.

Os manuais das escolas utilizados nos grandes colégios da França na primeira metade do século xviı contemplavam comentários de textos aristotélicos, interpretados principalmente nos Comentarii collegii conimbricensis, isto é, pelo curso de filosofia

4. Descartes examina, no Fragmento x dos Excerpta mathematica, a famosa resolução do caso dos ovais aplicados à Óptica (cf. AT, 10, p. 310). 
peripatética estabelecido no Colégio de Coimbra a partir de 1592. Descartes teve contato com os manuais das escolas desde meados de 1610, quando iniciou seus estudos no College La Flèche.

Assim, a principal referência de Descartes nesse período, diante do despertar de seu interesse por questões de óptica, é oriunda dos comentários de Christophorus Clavius, que propunha o estudo dos matemáticos clássicos, tais como Euclides, Apolônio e Pappus. Contudo, deve-se ressaltar que, para Clavius, as matemáticas mantinham ainda um status de ciência intermediária (cf. Jullien, 1996, p. 7). Invertendo a ordem seguida pelos manuais de óptica do século xvi, os quais iniciavam geralmente com um capítulo sobre a visão, Descar-

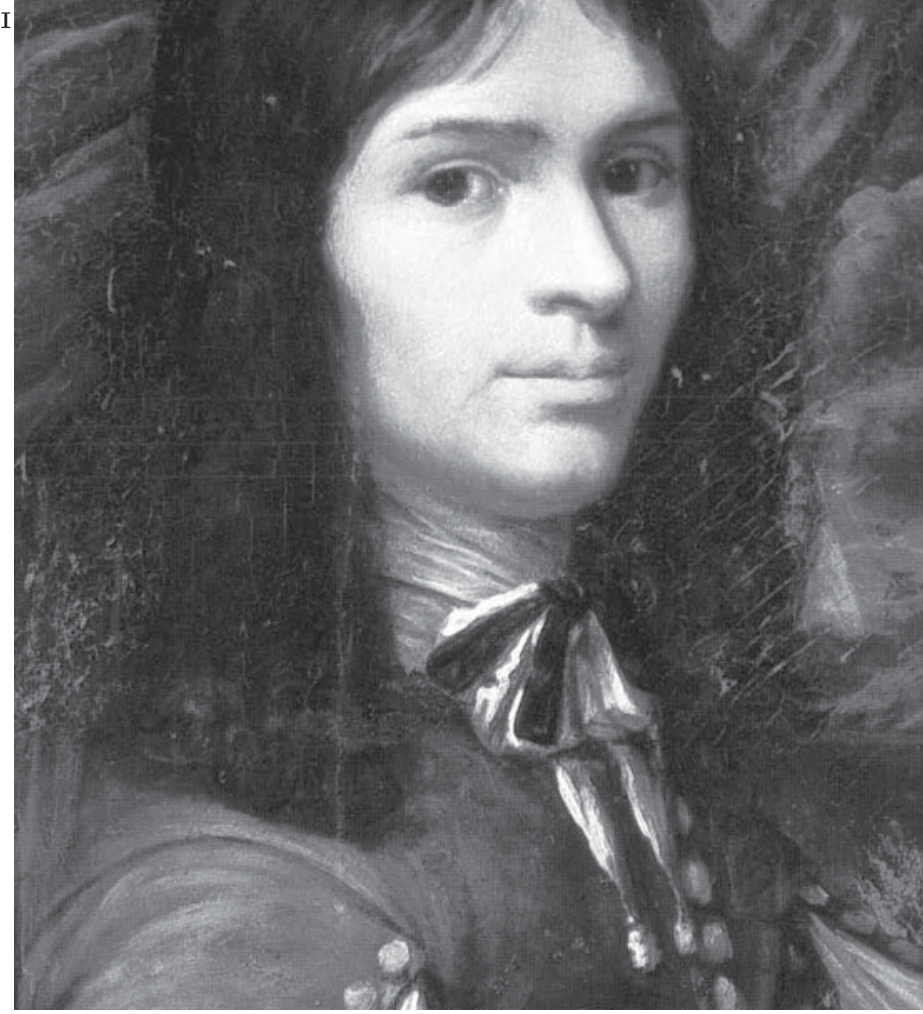

Figura 2. Descartes jovem. tes, aceitando a perspectiva kepleriana, inicia seu ensaio de óptica abordando aquilo que é passível de observação. Isso significa que Descartes considerava a óptica não mais como a ciência que permitia compreender o que é observável, mas que faz entender o porquê da observação e como ela se dá. 5

De acordo com Milhaud, Descartes, ao saber que Tycho Brahe e Kepler trabalhavam em Praga, "[...] bem tinha tentado ver os seus instrumentos" e, na ausência destes, "serviriam as obras impressas desses grandes sábios" (cf. Descartes apud Milhaud, 1921, p. 102). Além disso, Descartes escreve, em uma carta a Mersenne, que reconhece Kepler como o seu primeiro professor de óptica (cf. AT, 2, p. 86). Outro aspecto importante é o reconhecimento por parte de Descartes - em relação à obra de

5 Este é o ponto para lembrar que a correspondência de Descartes fornece amplos sinais da hostilidade que seus ensinamentos despertavam entre os "pensadores da Escola" - particularmente na área da óptica, em que, como Descartes descreve a Huygens em 1642: "Os escolásticos perseguiam minhas ideias, tentando cortá-las pelas raiz" (AT, 3, p. 523). E a sugestão de Balzac: "De resto, senhor, recordai, por favor, da história de vosso espírito; todos os nossos amigos aguardam e me prometestes.[...] Será um grande prazer acompanhar vossa aventura nas regiões e considerar vossas proezas contra os gigantes da Escolástica, a via que adotastes e o progresso que realizaste na busca da verdade" (AT, 1, p. 7-11). Gilson nos mostra também como o Ratio studiorum, regra de estudos dos jesuítas, que regia inclusive o ensino no colégio de La Flèche, orientava o aprendizado das matemáticas e de suas aplicações práticas, como as artes militares, a astronomia, a geografia, a hidrografia, a música, a óptica etc. (cf. Gilson, 1987, p. 129). 
Kepler -, ao anunciar que a matemática é o fundamento definitivo para as explicações científicas (cf. Milhaud, 1921, p. 102).

A outra fonte de investigação dos primeiros escritos de $A$ dióptrica é atribuída à correspondência de Descartes com alguns interlocutores da época. Por meio dessas cartas, sabe-se que Descartes dedicou-se a uma intensa investigação de óptica ao longo da década de 1620 e que estava ciente dos principais conceitos da tradição da óptica geométrica. Sabe-se também que Descartes realizou diversos experimentos ópticos com Mydorge e, sobretudo, com Ferrier, um artesão que construía instrumentos ópticos, e a quem Descartes solicitaria posteriormente a construção de lentes hiperbólicas. A proximidade entre Descartes e os artesãos de instrumentos ópticos é corroborada no início da Dióptrica: "E desde que a execução das coisas, de que falarei, deve depender da habilidade dos artesãos, que comumente não estudaram, procurarei mostrar-me inteligível a todos; e nada omitir do que se deve ter aprendido de outras ciências" (AT, 6, p. 82). Deve-se ressaltar que Descartes e seus interlocutores estavam interessados em demonstrar a curva anaclástica, ou seja, explicar como a forma de uma superfície de refração reúne os raios paralelos em um único ponto. Não por acaso, para essa explicação, Descartes utilizou as proporções geométricas da hipérbole: constatase, nessa demonstração, a articulação que Descartes efetua entre os raciocínios matemáticos e a demonstração física da anaclástica.

\section{A demonstração GARTESIANA dA ANAGLÁSTIGA}

A principal característica da demonstração física da anaclástica realizada por Descartes é de âmbito epistemológico. Nessa perspectiva, ressalta-se o modo com o qual o filósofo consegue tratar de um objeto físico por meio de uma concepção abstrata da matemática. Essa implicação epistemológica é anunciada por Descartes em uma carta datada de 27 de maio de 1638 a Mersenne. Nessa carta, Descartes relata o seguinte:

Perguntastes se considero que o que escrevi a respeito da refração seria uma demonstração. Pois penso que sim, ao menos na medida em que é impossível fornecer-vos uma demonstração nesta matéria, isto é, sem haver primeiramente derivado todos os fundamentos da física e da metafísica, algo que um dia espero realizar, mas que até o presente instante não os tenho em posse [...]. Exigir de mim demonstrações geométricas em um campo de investigação que depende da física é pretender que eu realize o impossível (AT, 2, p. 141-2). 
A solução para a impossibilidade apontada por Descartes consiste em apresentar como o método é concebido e aplicado. Um possível indício para essa concepção do método encontra-se na retomada da redação das Regulae ad directionem ingenii (Regras para a direção do espírito) em meados da década de 1620, com o intuito de restabelecer parâmetros que possibilitassem o conhecimento científico. Assim, em meados de 1626, Descartes voltou a interessar-se pelas questões relativas ao método. Colocara de lado, em 1620, suas tentativas iniciais de formular uma explicação do método. Retornou a tais questões com grande entusiasmo em 1626 ou 1627, ampliando e reelaborando suas "regras" anteriores, além de transformar todo esse exercício em algo bem diferente daquilo que havia contemplado fazer no fim de 1619 e em 1620. Na realidade, parte de sua nova exposição seria uma espécie de reelaboração de sua "matemática universal" dos primeiros tempos, apesar de muito transformada. Que Descartes retornou às Regulae com vigor renovado é evidente, mas, por quê? Não tinha havido nenhuma indicação, em 1620, de que ele pretendesse dar continuidade a esse texto. Ao contrário, depois de haver exposto as regras, simplesmente as abandonara, dedicando-se a estudos aplicados, isto é, a investigações de óptica. As regras posteriores foram dedicadas a questões relativas à cognição. A preocupação de Descartes na Regra 12, por exemplo, é com a cognição perceptiva e, desse modo, poder-se-ia conjecturar que estivesse dando continuidade a suas descobertas no campo da óptica. ${ }^{6}$

A demonstração da curva anaclástica é esboçada possivelmente pela primeira vez em uma carta datada em 13 de novembro de 1629 que Descartes enviou a Ferrier. Nessa

6 De acordo com Weber, ao abandonar a redação das Regulae 1620, Descartes havia rascunhado as primeiras onze delas; entretanto a Regra 8, em seu conteúdo conclusivo, é uma composição de um material aparentemente redigido em diferentes ocasiões. Proporciona a articulação entre as primeiras regras e as últimas. Segundo Weber, a Regra 8 é formada por quatro partes: 8A, o primeiro parágrafo; 8B, o título e o segundo parágrafo; 8C, os três parágrafos seguintes; e 8D, o restante do texto da regra. As partes 8A e 8B não tem coerência entre si, sendo, portanto, improvável que condigam com um texto contínuo; todavia, há fortes indícios de que datam do período das onze primeiras regras e as incoerências são de interesse menor. A maior importância reside na passagem de 8A/B para as partes maduras da regra, pois nessa transição é possível discernir como o pensamento de Descartes passou por uma relevante mudança. As primeiras regras eram determinadas por preocupações metodológicas e, sobretudo, pela questão do que constitui uma prova convincente de algo e do modo pelo qual é viável chegar a essa comprovação. A regra 8C oferece dois exemplos da aplicação do método cartesiano. O primeiro exemplo interpreta a descoberta da lei de refração e da curva anaclástica por meio da longa cadeia de razões desse método. Considerando-se o que vimos ter sido a trajetória provável para essa descoberta, a reconstrução do próprio Descartes merece ser examinada. Nas Regras 5 e 6, Descartes relata que "a determinação dessa curva depende da proporção que têm os ângulos de refração em relação aos ângulos de incidência”. Mas a matemática não mostra ao filósofo francês qual é essa proporção, e que não é possível apreendê-la a partir dos textos filosóficos e nem, tampouco, pela simples experiência sensorial, pois esta violaria a Regra 3, que instrui a confiar apenas nas coisas que se pode apreender de modo claro e evidente. Na Regra 5, Descartes relata que se deve decompor as proposições complexas em proposições simples. Weber desenvolve profundamente essa posição. E, em um trabalho posterior, elabora um exame sobre o método nas Regulae (cf. Weber, 1972, p. 25-49). 


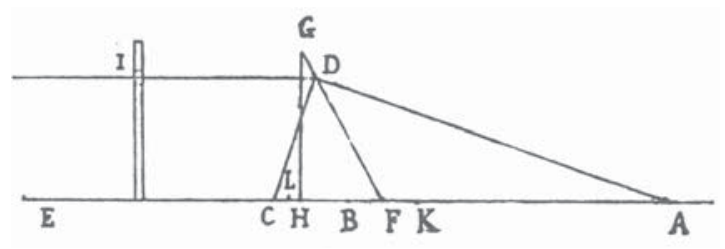

Figura 3 (AT, 1, p. 63).

carta, é possível constatar a articulação metódica que Descartes efetua entre os raciocínios matemáticos e a demonstração física da anaclástica. Essa articulação metódica é realizada da seguinte maneira: Descartes relata que é necessário traçar a linha do ponto A ao ponto B do triângulo identificado nos pontos FGH e, por conseguinte, deve-se traçar uma linha do ponto $\mathrm{G}$ ao ponto $\mathrm{H}$ (ver figura 3). Diante disso, constata-se que, de qualquer grandeza que possa ser efetuada a linha GH, constitui-se o ângulo reto com os pontos AE. Desse modo, para Descartes, o raio luminoso passará pelo ponto I e, assim, seguirá em sua determinação até o ponto D (cf. AT, 1, p. 62-3). Deve-se ressaltar que, para Descartes, apenas haverá refração quando o raio luminoso alcançar o ponto D. Por isso, Descartes solicita ao artesão Ferrier que observe atentamente a linha CDF. Isso porque essa linha representa a inclinação do vidro dentro do qual ocorre a refração no ponto D. Descartes acrescenta ao artesão que o ponto D é cortado pelo raio de luz e é no ponto A que o raio luminoso corta a linha que forma o quadrante. Nessa perspectiva, identifica-se o ângulo ADF. Então, segundo Descartes, do ponto D deve-se traçar uma outra linha constituindo os pontos DC, de tal modo que o ângulo FDC seja equivalente ao ângulo ADF. Desse modo, Descartes conjectura que, se propusesse o raio nos pontos ID, a luz refratar-se-ia no ponto D e, por conseguinte, se determinaria no ponto A. O passo seguinte é traçar a linha DC que, por sua vez, corta o esboço geométrico configurado em um tablado através dos pontos das extremidades da linha reta EA em C (cf. AT, 1, p. 62-3). Descartes mostra, assim, que o ângulo composto pelos pontos CDF é equivalentemente proporcional aos pontos que constituem o ângulo ADF. Desse modo, Descartes elabora a lente óptica através das medidas proporcionais da hipérbole. $\mathrm{O}$ molde dessa lente, portanto, permite que um feixe de raios de luz paralelos que a atingem se convertam em raios convergentes a um único ponto. Eis, portanto, o primeiro indício matemático para a resolução da forma anaclástica.

Constata-se, assim, que Descartes descobre a lei de refração em meados de 1629, a partir do cálculo da hipérbole que ele atribuiu à construção da forma da anaclástica. A lei de refração é concebida quando Descartes observa que um raio de luz passa de um meio para um outro: constata-se que o seno do ângulo de incidência mantem uma razão constante com o seno do ângulo de refração. Embora Descartes não forneça em Adióptrica uma descrição literal da lei dos senos a partir dos experimentos físicos, sustenta-se que a concepção matemática da lei dos senos foi determinante no empreendimento científico de Descartes em $A$ dióptrica. Isso porque é possível perceber, por meio das proporções geométricas descritas nessa obra, o conhecimento prévio da lei dos senos. 
Snellius, professor de matemática em Leyden, havia formulado a lei de refração, entretanto, com uma formulação (na qual o índice de refração se igualava à razão sen r/ sen i) completamente diferente da formulação cartesiana. Ressalte-se ainda que Snellius nunca chegou a publicar sua formulação da lei de refração (cf. Korteweg, 1986). Huygens chegou a ler o manuscrito de Snellius, o qual descrevia o modo como demonstrar a lei de refração, concluindo precipitadamente que Descartes se havia apossado das ideias de Snellius. 7 Todavia, sabe-se que Descartes já havia chegado à lei de refração antes 1629, e que não há nenhuma possibilidade de que antes desse ano ele tivesse tomado conhecimento da descoberta realizada por Snellius. Ademais, quando Descartes explica a sua descoberta da lei dos senos a Jacobus Golius - o sucessor acadêmico de Snellius em Leyden - , em fevereiro de 1632, este, além de não comentar que Snellius havia obtido um resultado similar, homenageou Descartes como o descobridor de uma via totalmente inovadora para a demonstração da lei de refração (cf. Korteweg, 1986).

\section{Um possível indício da demonstração da Lei de ReFração em $A$ dióptrica}

Sustenta-se que quando Descartes realizou os experimentos de $A$ dióptrica, por meio do uso metodológico de hipóteses e analogias, ele pretendia demonstrar uma lei matemática previamente descoberta. Essa era a lei dos senos: que seria empregada para a formulação da lei de refração.

Nos Discursos I e II de $A$ dióptrica, Descartes realizou três empreendimentos científicos com o intuito de demonstrar o caráter apriorístico da matemática. O último empreendimento científico, quando Descartes utiliza a analogia do deslocamento da bola para compreender o movimento da luz, mostra o modo como ele pretendia estabelecer a lei de refração. Segue-se uma possível explicação do modo como Descartes demonstrou a lei de refração na Dióptrica. De todas as partes do movimento que se po-

\footnotetext{
7 Por meio de alguns dados históricos, Rodis-Lewis afirma que: "Descartes teria tomado de Snellius o manuscrito que descrevia o modo como demonstrar a lei de refração. Com efeito, Snellius a teria formulado antes de morrer, isto é, em 1626, e sem a ter publicado. Sê-lo-á em 1632 por um amigo de Descartes, Golius. Mas desde a sua chegada aos Países Baixos, ou seja, no final de 1628, Descartes enunciou-a corretamente. E em uma carta latina a Huygens, de 1 de novembro de 1632, Golius sublinhará a diferença: o francês [Descartes] encontrou a lei dos senos pelos seus princípios e causas; o neerlandês [Snellius] pelos efeitos e suas observações. Por intermédio de Mydorge, Descartes havia estabelecido amizade com o excelente artesão Ferrier que, segundo as suas indicações, cortou tão bem uma lente hiperbólica que se pôde verificar a convergência dos raios após terem atravessado o vidro da lente." (RodisLewis, 1996, p. 94). Ora, note-se que Jacobus Golius atribui a elaboração cartesiana da lei a princípios e causas, ou seja, Descartes encontra a lei dos senos mediante procedimentos intelectuais conferidos através das cognições puramente matemáticas ou, em outras palavras, pela geometria analítica, enquanto Snellius encontrara por intermédio dos efeitos, ou seja, pela demonstração física.
} 


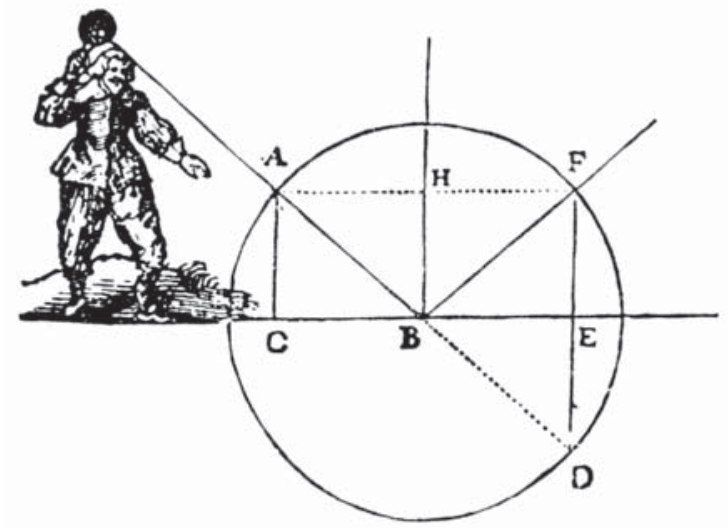

Figura 4 (AT, 6, p. 93).

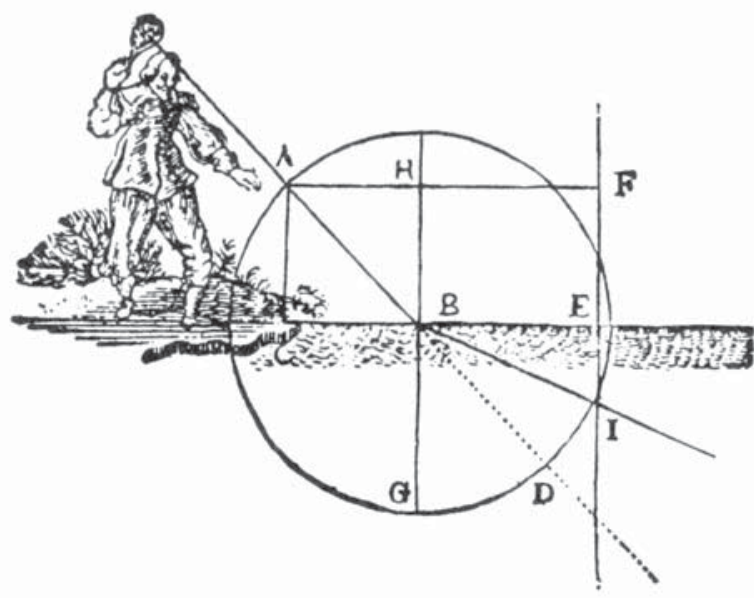

Figura 5 (AT, 6, p. 98).

diam imaginar em AB, Descartes escolheu as determinações/ direções AC, perpendicular à superfície, e AF, paralela (ver figura 4). No momento do impacto, conjecturava-se que a superfície impediria a primeira determinação, porém não no caso da segunda. Em outras palavras, o movimento de AC encontraria um obstáculo, sem que fosse necessária a mudança da paralela AF. A partir dessa cadeia de raciocínios, Descartes descreve o percurso que a bola seguirá depois de colidir com a superfície, desenhando um círculo com centro em $B$, de raio $A B$ (ver figura 5 ). Como a velocidade da bola não é alterada, se moverá de $\mathrm{B}$ até o ponto $\mathrm{F}$ na circunferência do círculo no mesmo tempo em que chegará em D. Em seguida, Descartes determina o ponto $F$ baseando-se no pressuposto de que a determinação paralela não muda após a colisão. Diante disso, para Descartes, a bola deverá equidistar de $\mathrm{H}$ e cair em linha reta FD paralela a HB e AC (cf. AT, 6, p. 98).

Continuando sua demonstração, Descartes afirma que se produzirá "o mesmo efeito se a bola encontrar no ponto B um corpo de natureza tal que ela passe através de sua superfície CBE, um terço mais facilmente do que através do ar" (AT, 6, p. 100). Assim, a trajetória física do raio refratado BI é determinada tomando $\mathrm{BE}=2 / 3 \mathrm{BC}$, e desenhando a perpendicular FE, que corta o círculo em I (ver figura 6).

É possível, assim, admitir que a razão CB/BE é o modo pelo qual a lei dos senos aparece em $A$ dióptrica de Descartes. A forma moderna, sen $i=\operatorname{sen} r$ (onde $i$ é o ângulo de incidência, $r$ o ângulo de refração, e $n$ uma constante específica do meio refrativo) é manifesta no círculo, que descreve o percurso do movimento da bola, onde $\mathrm{ABH}$ é o ângulo de incidência e IBG é o ângulo de refração.

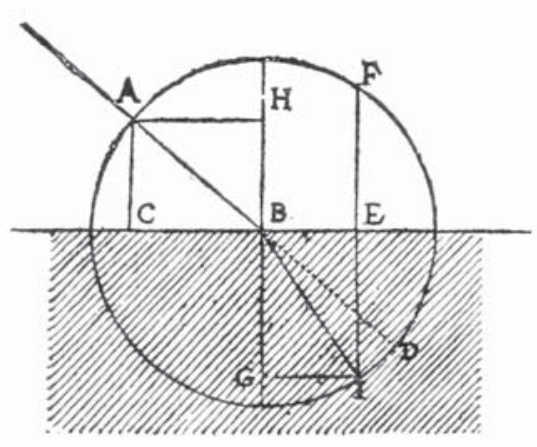

Figura 6 (AT, 6, p. 100). 
Ora, sen $i=A H / A B$, e sen $r=G I / B I$;

mas $\mathrm{AB}=\mathrm{BI}=1$, pois $\mathrm{AB}$ e $\mathrm{BI}$ são raios do círculo;

$\operatorname{logo}, \operatorname{sen} i=A H$ e $\operatorname{sen} r=G I$.

Entretanto, $\mathrm{AH}=\mathrm{CB}$, e $\mathrm{GI}=\mathrm{BE}$, de modo que sen $i=\mathrm{CB}$ e sen $r=\mathrm{BE}$.

É provável que Descartes partisse dessa formulação da lei dos senos para que, por exemplo, Ferrier observasse diretamente no diagrama quais seriam as linhas que deveriam ser mensuradas. Entretanto, para a formulação efetiva da lei de refração, Descartes deveria ainda levar em consideração algumas variáveis físicas.

O passo determinante do argumento cartesiano considera a redução da metade da velocidade do movimento da bola. Eis, portanto, a principal variável física que deveria ser considerada. Para o desdobramento desse raciocínio, é necessário estabelecer duas considerações, a saber: por um lado, Descartes afirma que a componente horizontal do movimento da bola permanece inalterada, e apenas o que muda é a parte da determinação que faz com que a bola tenda a mover-se para baixo; por outro lado, relata que a determinação da velocidade ocorre ao longo da trajetória física do movimento da bola, ou seja, ao longo da superfície CBE (ver figura 6). Descartes acrescenta que, na suposição de que a bola tenha perdido "a metade da velocidade ao atravessar a tela CBE, para ir de B a qualquer ponto do círculo AFD, deverá utilizar o dobro do tempo que levou de A para B" (AT, 6, p. 100).

Constata-se, assim, que Descartes possuía o conhecimento prévio da lei dos senos: portanto, o que é descrito em $A$ dióptrica não é o processo de descoberta, mas apenas a demonstração/justificação experimental de uma lei matemática. É necessário, portanto, distinguir o processo de descoberta de uma lei matemática (lei dos senos) do modo como Descartes demonstra o movimento da luz (lei de refração). Deve-se ressaltar que essa diferenciação é decorrente do modo como Descartes concebe e aplica o método.

\section{UMA POSSÍVEL INTERPRETAÇÃO DO MÉTODO GARTESIANO}

Segundo Garber (cf. 2004, p. 118), o método de Descartes é ilustrado no exemplo descrito na Regra 8. De acordo com ele, o método de Descartes comporta apenas duas etapas: uma etapa redutiva, na qual as proposições complicadas são reduzidas a proposições mais simples, e uma etapa construtiva, em que é possível regressar das proposições mais simples em direção das mais complexas. Para Garber, o problema que Descartes se propõe é o da investigação da composição da linha anaclástica. Então, Descartes observa, naquilo que parece ser a primeira etapa de redução, que a determinação dessa linha depende da proporção que é observada entre os ângulos de refração e os ângulos 
de incidência. Mas, para Descartes, essa questão é ainda composta e relativa, isto é, insuficientemente simples; e, assim, é necessário ir mais longe na aplicação da redução do fenômeno. Diante disso, Garber considera que Descartes recusa toda investigação empírica da relação em questão, pois o filósofo francês explicara que se deve, em um segundo momento, perguntar-se como se faz com que a relação entre os ângulos de incidência e os ângulos de refração seja causada pela diversidade do meio, por exemplo, o ar e o recipiente que estão a sua volta, o que suscita a questão de saber como o raio de luz penetra através de todo corpo diáfano. Para o conhecimento dessa penetração, supõese que a natureza da ação da luz seja conhecida. Porém, para compreender a natureza da luz, é necessário saber o que é uma potência natural (potentia naturalis). É nisso, segundo Garber, onde termina a aplicação da redução. Diante disso, Descartes parece pensar que é possível conceber a natureza do fenômeno por uma intuição apreendida pelo entendimento: intuição de que se trata de uma potência natural (cf. Garber, 2004, p. 118).

A partir de outras passagens, sugere-se que a mencionada intuição está em estreita ligação com o movimento, pois, uma vez que se possui tal intuição, é possível começar a etapa de composição/construção e seguir pela questão original, tratando da linha anaclástica. Isso implica que se compreenda a natureza da ação da luz a partir da natureza de uma potência natural, portanto, que se compreenda a maneira pela qual os raios penetram nos corpos transparentes a partir da natureza da ação da luz e da relação que há entre o ângulo de incidência e o ângulo de refração. Enfim, uma vez que se identifique a relação que há entre esses ângulos, pode-se resolver o problema da linha anaclástica (cf. Garber, 2004, p. 119).

\section{A deScoberta MATEMÁtica dos ÂNGULOS DE INGIDÊNCIA E REFraÇÃo}

A explicação matemática da hipérbole e a demonstração física da anaclástica, descritas na carta a Ferrier, retomam os passos do método relatado por Descartes na Regra 8 das Regulae. Por meio dessa interpretação dos textos cartesianos é possível presumir que Descartes possuía, desde 1629, a lei dos senos e, por consequência, as leis de incidência e refração da luz. Admite-se, assim, que o principal tema de $A$ dióptrica, a saber, a demonstração dos ângulos de incidência e refração da luz, era conhecido por Descartes desde meados da década de 1620.8

Para Costabel, a primeira parte da Regra 8 descreve a anaclástica a partir da situação histórica em que Descartes estava inserido (cf. Costabel, 1982, p. 56-7). Nessa

8 Desde 16 de março de 1626, Cernier perguntava a Mersenne se “esse excelente matemático de que falais poderá explicar as razões das refrações". E, em 22 de março de 1626, declara: "Ficar-vos-ei grato, e a M. des Chartes, quando me participarem o seu extraordinário método e as suas magníficas descobertas ópticas” (Mersenne, 1625, 1, p. 412-29). 
perspectiva, Costabel revela que Descartes fez parte do círculo de Mersenne e, por isso, teve notícias, na década de 1620, das obras de Kepler (reflexões teóricas e experimentais) e das obras de Mydorge (contribuições referentes à descoberta da hipérbole para descrição analítica da anaclástica). Quanto a Kepler, segundo Schuster (cf. 1977, p. 3o4-54), ele demonstrou que o princípio da imagem falhava em alguns casos, como quando os raios se aproximam da superfície em um ângulo bastante oblíquo. Kepler usa um artifício geométrico muito semelhante ao de Descartes. Todavia, há uma imensa distinção entre a geometria de Kepler e a maneira pela qual Descartes descobre, por exemplo, a lei dos senos. Descartes empreende a busca de uma razão constante, ou seja, procura encontrar um par de linhas geometricamente proporcionais que possibilite relacioná-las com os senos dos ângulos de incidência e refração. Segundo Schuster, Beeckman muito provavelmente mostrou a Descartes seus cadernos de apontamentos, os quais revelavam que, desde meados de 1628, ele vinha lendo criteriosamente os textos de astronomia de Kepler; e, assim, procurando formular uma óptica mecânica. Em um procedimento que lhe era comum, e que Descartes aprende com ele, Beeckaman detalha o trabalho de Kepler, não com o intuito de questionar seus resultados, mas com o objetivo de reconstruir esses resultados sobre fundamentos mais seguros.

Quanto à influência matemática de Mydorge, parece que ela contribuiu para o conhecimento das cônicas por parte de Descartes, conhecimento que possibilitou a Descartes examinar a sugestão de Kepler relativa à aplicação da hipérbole na demonstração da anaclástica (cf. Schuster, 1977, p. 304-354). De acordo com Costabel (cf. 1982), a segunda parte da Regra 8 demarca a intervenção de Descartes no assunto da anaclástica. Nesse contexto, Descartes opõe-se a Kepler e pretende descrever a refração da luz através da lei dos senos, para tanto, empreendendo passos semelhantes aos de Mydorge.

Segundo Costabel, o plano da investigação, que Descartes expõe na segunda parte da Regra 8, supõe, no entanto, ultrapassado o estado em que a justificação da lei dos senos é situada em uma analogia estática, tal como o era ainda no caso de 8 de outubro de 1628 (cf. Costabel, 1982, p. 57). É provável que a alegria de Descartes - diante do fato de que Beeckman fornecera a demonstração da hipérbole anaclástica - marque o início de uma confiança na exatidão da lei dos senos. Tratava-se, desde então, de produzir uma prova satisfatória e Descartes podia esperar que a partir da aposta em concepções novas que estavam em curso, as quais conduziram Descartes, em $A$ dióptrica, à analogia dinâmica, o problema matemático da anaclástica poderia ser resolvido.

Porém, segundo Costabel, uma coisa é aplicar a analogia que conduz à lei dos senos para a refração e outra coisa é a solução da anaclástica. A lei dos senos consiste em determinar uma curva por uma condição definida com a tangente, isto é, resolver um problema inverso ao da tangente, ou uma equação diferente da primeira ordem (cf. Costabel, 1982, p. 57). Escrevendo, no fim da segunda parte de sua exposição da 
Regra 8, "que não vê o que pode impedir de conseguir", Descartes revela que escreve em um momento em que ainda não tinha a concepção da natureza matemática da dificuldade. Descartes acredita que a demonstração de Beeckman, a qual consiste em mostrar que uma hipérbole soluciona a questão, pode servir para a demonstração mais geral de que apenas as seções cônicas realizam aquilo que se pretende. Essa demonstração surge no final do inverno de 1628-1629, ou um pouco depois (cf. Costabel, 1982, p. 57).

É pertinente examinar quais foram as relações que existiram entre a descoberta da lei de refração de Descartes e a de Mydorge por meio dos comentários de Pierre Costabel. Ele afirma que a solução de Descartes avalia a razão constante, isto é, a característica do fenômeno como razão das velocidades (cf. Costabel, 1982, p. 75). A razão
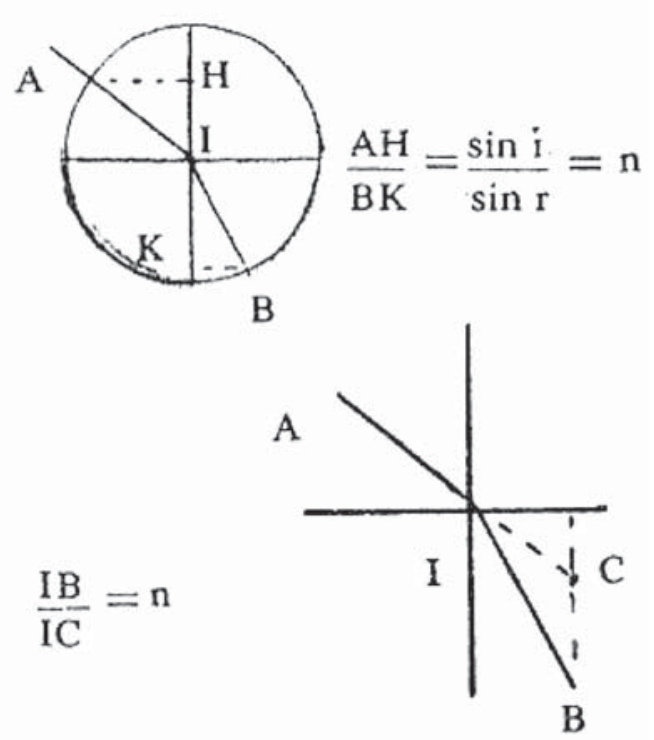

Figura 7 (Costabel, 1982, p. 75). das velocidades é adquirida a partir da teoria das proporções. Essa razão, portanto, explica a facilidade de penetração diante da aplicação do experimento óptico. Assim, encontra-se a razão das distâncias (ou das hipotenusas) consideradas por Snellius (ver figura ₹). Portanto, a equivalência matemática encontra-se dessa maneira presente no próprio texto de Descartes.

Desse modo, constata-se que (1) um fator é a forma matemática equivalente e (2) outro fator é o que diz respeito aos diferentes e sucessivos usos que podem ser realizados pelo físico. Por meio das indicações de Huygens, admite-se que a proporção descrita por Snellius requer relação com o problema da imagem que o olho do observador percebe no fundo de um vaso cheio de água, a saber, as formas do objeto empírico (cf. Costabel, 1982, p. 75). Para essa descrição, a teoria das proporções de Snellius é eficaz, entretanto, sem bases explicativas em outras possibilidades reais de experimentações ópticas. De outro modo, a proporção dos senos é, para Descartes, ao mesmo tempo eficaz e operacional, pois permite a representação da anaclástica. Desse modo, o uso da teoria das proporções de Descartes é suscetível de uma melhor comprovação, isto é, em relação a uma mera verificação experimental. Essa diferença demarcada na história da física-matemática solicita prudência no julgamento a partir das equivalências matemáticas que Descartes impõe às descobertas anteriores de Snellius (cf. Costabel, 1982, p. 75). 
Na proposição 1, Mydorge (cf. Gaukroger, 2002, p. 186-8) demonstra que dado um raio incidente $\mathrm{FE}$, refratado numa superfície $\mathrm{ABE}$, e o raio refratado em EG, se conhecem o ângulo de incidência CEF e o ângulo de refração GED, com os quais se pode descobrir a refração de qualquer outro raio incidente HE. Para tanto, é necessário escrever um se-

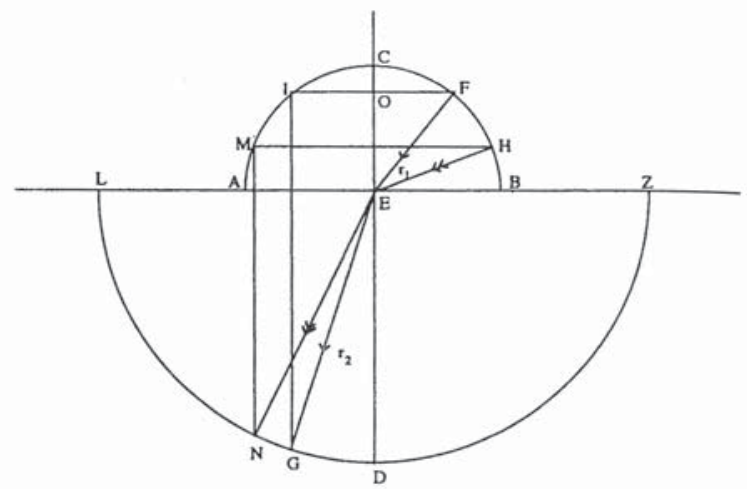

Figura 8 (Gaukroper, 1999, p. 186). micírculo ABC com qualquer raio, exemplo em EB, e em torno de E, com a circunferência cortando EF em F e HE em H. Depois traça-se IF paralelamente a AB. Partido de I, onde IF intersecta o semicírculo ACB, traça-se uma linha IG para baixo, paralelamente a CE. IG cortará EG no ponto G. Então, EG passa a funcionar como o raio do semicírculo LDZ, a ser traçado em torno de E. Tem-se, assim, um procedimento para descobrir a refração buscada de HE. Basta traçar HM, paralelamente a BA e, partindo do ponto M, interseção de HM com o semicírculo ACB, faz-se uma linha paralela a CED. Essa linha paralela, MN, intersectará LDZ no ponto N. O raio refratado, que se deseja encontrar, será EN. A demonstração baseia-se no princípio da proporção constante entre os raios de dois círculos diferentes, e a sua forma trigonométrica equivale à prova de que cosec $i / \operatorname{cosec} r=r_{1} / r_{2}$.

Ora, as duas descobertas da lei dos senos por Harriot e Snellius resultam na versão da cosecante, o mesmo ocorrendo na exposição de Mydorge. ${ }^{9}$

A reconstrução de Schuster, visando à descoberta da lei da cosecante para a refração da luz, baseia-se em dois conhecidos princípios, conforme exposto a seguir (cf. Schuster, 1977, p. 3०4-54). O primeiro princípio propõe que se devem considerar dois meios ópticos separados pela superfície $\mathrm{AOB}$, sendo, pois, o meio inferior o mais denso. Para localizar a imagem do ponto E, é necessário estender o raio refratado OF até o meio

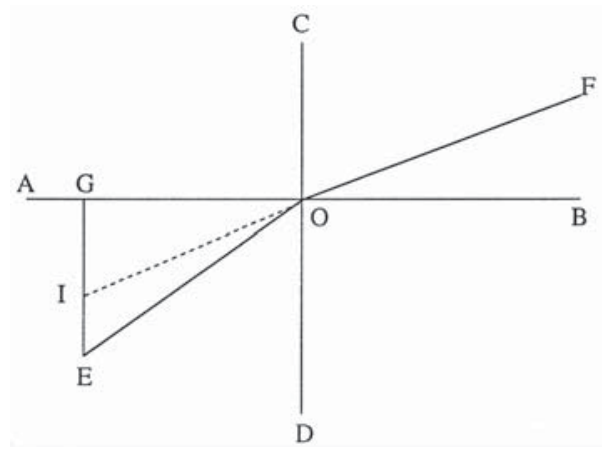

Figura 9 (Gaukroper, 1999, p. 187).

9 Ao reportar-se à constituição da lei dos senos, Cottingham acrescenta que: "Descartes expõe uma versão daquilo que nos nossos dias se conhece como a lei Snellius, segundo a qual o seno $i=n$. sen $r$, onde $i$ é o ângulo de incidência, ro ângulo de refração e $n$ a constante específica do meio refrator" (Cottingham, 1993, p. 102). Jullien acrescenta que a lei de refração, ou lei dos senos, fornece a explicação da maneira como um raio de luz é desviado quando passa de um meio para um outro (cf. Jullien, 1996, p. 105). 
inferior e marcar sua interseção com EG, a perpendicular que vai de $E$ até a superfície AOB. O segundo princípio decorre de uma característica do refratômetro de Ptolomeu. Esse instrumento é constituído por um disco de bronze $A B C D$, que tem um visor fixo

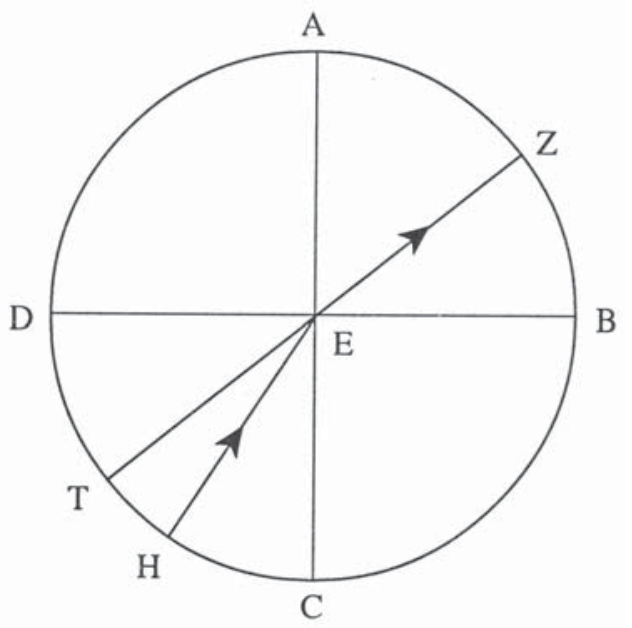

Figura 10 (Gaukroger, 1999, p. 188). em $\mathrm{E}$, e visores móveis em $\mathrm{Z}$ e $\mathrm{H}$, ajustáveis ao longo da circunferência. Então, o disco é colocado na superfície da água, de modo que DEB acompanhe exatamente essa superfície. Observa-se pelo visor que, ao longo de ZE num ângulo de incidência AEZ, o disco move-se de $\mathrm{H}$ até coincidir com a linha da visão. $\mathrm{O}$ percurso do raio refratado que parte do objeto pontual H é então fornecido por ZE e EH.

Constata-se, assim, que a via da descoberta da lei implicaria os seguintes pressupostos: primeiro, a suposição de que a regra da imagem é válida e reveladora do fenômeno da refração; segundo, a disposição dos dados empíricos em ângulos de incidência e de refração, derivados de Ptolomeu através de Vitélio; terceiro, a aplicação da regra da imagem aos raios desenhados.

A explicação de Mydorge, na Proposição 1, é bastante compatível com o fato de ele haver descoberto a lei. Verifiquemos uma possível formulação para a lei dos senos nas explicações de Mydorge. As proposições 2-5 do relatório de Mydorge tratam sobre a teoria das lentes. A proposição 2 utiliza a forma da lei pautada na cosecante, embora a lei do seno fosse mais fácil de manipular. Todavia, em um corolário da proposição 2, assim como na proposição 5, Mydorge percebe que é necessário passar da versão cosecante para a versão do seno. Portanto, para demonstrar que a hipérbole é uma superfície anaclástica, Mydorge deve fazer a passagem da versão da cosecante para a do seno, não por alguma razão ligada a seu modo de conceber o percurso dos raios reais, pois o autor considera claramente que o percurso dos raios reais é captado nos raios constantes dos dois círculos desiguais, mas porque a geometria da demonstração requereria essa mudança de uma forma de relação para sua forma trigonometricamente equivalente. Ademais, na proposição 3 , o autor oferece uma prova sintética com referência às hipérboles, que tem como decorrência efetiva a proposição 4, que se refere às elipses.

Contudo, Descartes, embora reconheça a importância das contribuições dos seus interlocutores e antecessores para os empreendimentos de suas pesquisas em óptica, propõe-se a elaborar um método universal engendrado nas certezas de uma inovadora 
concepção matemática. Consagra-se, assim, à elaboração da geometria analítica, a fim de aplicar tais cálculos às descrições físicas, sobretudo, às demonstrações ópticas. É, portanto, por meio dos cálculos da geometria analítica que Descartes adquire a segurança para publicar as suas inovadoras demonstrações científicas em $A$ dióptrica. ${ }^{10}$ Um exemplo que ilustra os cálculos da geometria analítica, instrumentalizados nas demonstrações ópticas, é o caso da explicação dos quatro gêneros de ovais (cf. AT, 6, p. 424). Essa exemplificação é descrita no segundo livro de $A$ geometria. Descartes relata nessa obra que as linhas curvas têm diversas propriedades que não extrapolam a natureza das seções cônicas e, por isso, são também designadas como figuras plenamente inteligíveis. Diante disso, Descartes sustenta que é possível explicar certos tipos de ovais que podem ser utilizados na catóptrica e na dióptrica. ${ }^{\mathbf{1 1}}$

A construção das ovais é manifesta quando Descartes dedica-se a mostrar a utilidade instrumental de sua matemática no campo da óptica. Além disso, deve-se assinalar que as ovais de Descartes possuem a propriedade de fazer com que os raios de luz convirjam a um único ponto. Verifiquemos o modo como Descartes descreve a demonstração das ovais em $A$ geometria.

Descartes expõe o primeiro modo para construir a figura de óptica da seguinte maneira: primeiramente, são traçadas as linhas retas FA e AR (ver figura 11). Em seguida, deve-se tomar, de modo arbitrário, em uma dessas linhas o ponto F, isto é, relativamente distanciado do ponto A (AT, 6, p. 424-5). Do ponto F como centro, devese escrever o círculo que passa pelo ponto 5 ,

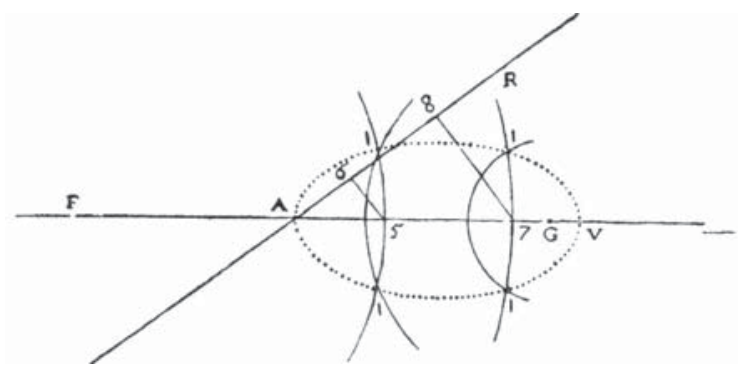

Figura 11 (AT, 6, p. 424). do qual é obtida a linha reta 56, que corta a outra linha no ponto 6, de modo que a linha A6 seja menor que $A_{5}$ em uma dada proporção. Essa proporção irá medir as refrações.

10 EmA geometria, Descartes relata, ao tratar da demonstração dos ovais referentes às reflexões e as refrações, que: "mas ainda é necessário que satisfaça o que omiti em $A$ dióptrica, ao anunciar que podem haver lentes de várias formas que podem fazer com que os raios que partem de um mesmo ponto do objeto se juntem todos em um mesmo ponto depois de tê-las atravessado e que, entre essas lentes, as que são demasiadamente convexas de um lado e côncavas de outro têm mais força para irradiar que as que são igualmente convexas dos dois lados: enquanto que, pelo contrário, estas últimas são melhores para as lunetas. Desse modo, limito-me a explicar as mais convenientes, supondo, na prática, as dificuldades que possivelmente os artesãos teriam para talhá-las" (AT, 6, p. 4.34).

11 Mersenne fornece na obra La vérité des sciences a explicação dos conceitos de catóptrica e dióptrica. Catóptrica é a parte da óptica que trata da reflexão. Com origem no termo grego opsis (visão) e o prefixo kata (para baixo), isto é, refletido. Opõe-se á dióptrica, que di, forma do prefixo dia - usada antes de vogal - significa "através de", donde di-óptica, parte da óptica que trata da refração, ou seja, do movimento da luz através de meios transparentes (cf. Mersenne, 1625, p. 229-30). 
É para esse objetivo que é aplicada na óptica. Em seguida, deve-se determinar o ponto $\mathrm{G}$ na linha FA, ou seja, do lado em que está o ponto 5 . Então, deve-se determinar que as linhas AF e GA tenham entre si a proporção desejada. Faz-se RA igual à GA na linha A6. Nessa linha, com centro em G, é descrito o círculo cujo raio é igual a R6. Esse círculo cortará o outro de um lado e de outro no ponto 1. Portanto, esse círculo é aquele por onde se inscreve a primeira das ovais. ${ }^{\mathbf{1 2}}$

De acordo com Descartes, com o centro em F, descreve-se o círculo que passa pelo ponto 7 (AT, 6, p. 425). Então, traça-se a linha reta $7^{8}$ paralela a $5^{6}$ e, com centro em $\mathrm{G}$, deve-se escrever outro círculo cujo raio é igual à linha R8. Esse círculo corta o que

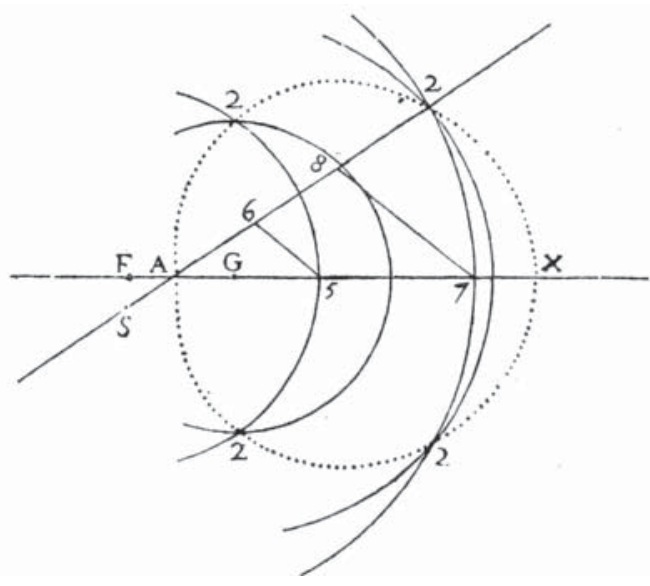

Figura 12 (AT, 6, p. 426).

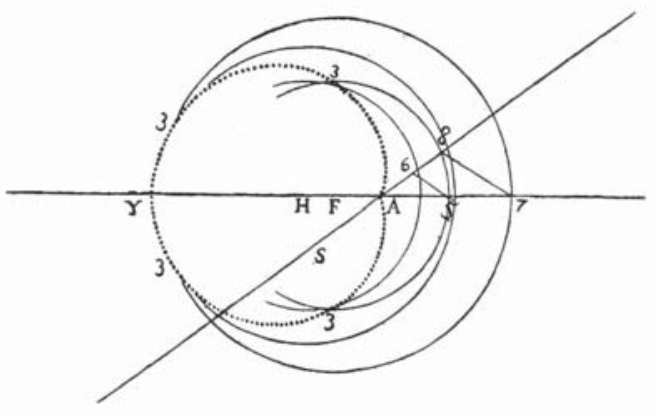

Figura $13($ AT, 6, p. 427). passa pelo ponto 7 no ponto 1. Portanto, é outra da mesma oval (ver figura 12). E assim encontram-se tantas outras quanto se desejar, ou seja, traçando outras linhas paralelas a 78 e outros círculos de centros F e G.

Segundo Descartes, para a descrição da segunda oval é necessário colocar, no lugar de AR, AS igual a GA. Assim, o raio do círculo descrito do centro $\mathrm{G}$ corta o raio descrito do centro F. Esse passa pelo ponto 5. Portanto, o ponto 5 é igual à linha S6. Mas o ponto 5 pode ser também igual a $\mathrm{S} 8$, isto é, caso seja necessário cortar o que passa pelo ponto 7. Através do ponto 7, os círculos se cruzam nos pontos marcados pelo número 2. Tais pontos são dessa segunda oval, ou seja, $A 2 x$.

Para a descrição da terceira e quarta oval (ver figura 13), Descartes considera ser necessário colocar no lugar da linha AG, AH do outro lado do ponto A, ou seja, no mesmo local no qual está o ponto $\mathrm{F}$ (cf. AT, 6, p. 426). Note-se que a linha AH deve ser maior que AF. Desse modo, o ponto F encontra-se onde está o ponto A, ou seja, no traço de todas as demais ovais. Em seguida, 
das linhas AR e $\mathrm{A}_{5}$, deve-se traçar a terceira oval A3Y, a qual é descrita em um círculo de centro $\mathrm{H}$ cujo raio é igual a S6. A terceira oval corta no ponto 3 o círculo de centro $\mathrm{F}$ e raio $\mathrm{F}_{5}$. A terceira oval corta também o outro círculo, cujo raio é igual a S8. Esse raio corta o que passa pelo ponto 7 no ponto marcado 3 (cf. AT, 6, p. 426-7).

Para a última oval é necessário escrever círculos de centro $\mathrm{H}$ cujos raios são iguais às linhas R6 e R8. Essas linhas cortam os outros círculos nos pontos marcados 4 (ver figura 14). De acordo com Descartes, pode-se ainda encontrar uma infinidade de outras maneiras para descrever essas mesmas ovais. Assim, por exemplo, pode-se traçar a primeira oval AV (ver figura 15) quando se conjetura que as linhas FA e AG são iguais, o que possibilita que se divida a linha FG no ponto L, de modo que FL esteja para LG, como $\mathrm{A}_{5}$ está para A6. Ou seja, que essas medidas tenham a proporção que mede as refrações (cf. AT, 6, p. 427-8). Assim, tendo dividido AL em duas partes iguais pelo ponto $\mathrm{K}$, faz-se girar uma régua ao redor do ponto $\mathrm{F}$. Então, tensionando com o dedo $\mathrm{C}$ a corda KCG, fixada nos extremos Ke G, de modo tal que o tamanho dessa corda seja formado pelas linhas GA mais AL mais FE menos AF (cf. AT, 6, p. 428). Portanto, é o

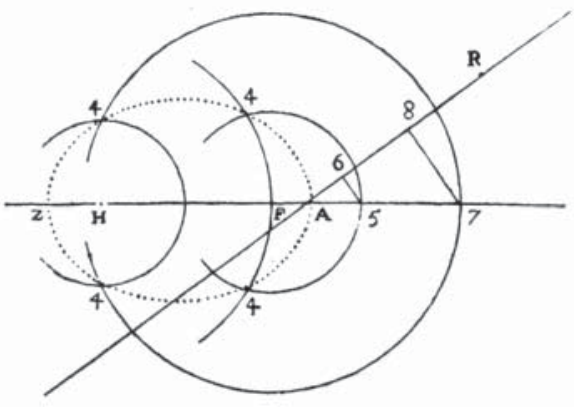

Figura 14 (AT, 6, p. 427).

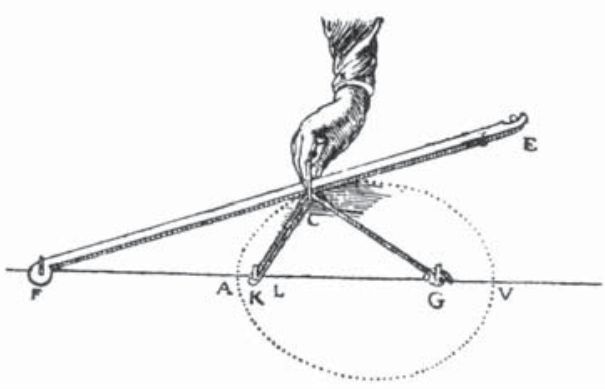

Figura ${ }_{5}$ (AT, 6, p. 428). movimento do ponto $\mathrm{C}$ que descreve a oval, tal como é estabelecido em $A$ dióptrica por Descartes. ${ }^{13}$ Sendo assim, Descartes utiliza os casos que contemplam a natureza das elipses e da hipérbole para descrição das ovais (cf. AT, 6, p. 4,28).

Sabe-se que para realizar a fabricação de lentes hiperbólicas por meio da forma anaclástica, Descartes empreendeu o estudo das ovais, desenvolvido mediante a metodologia de jardineiros, as quais são descritas em $A$ díóptrica (AT, 6, p. 165-6). Esse estudo fornece o primeiro exemplo de curva definida e analisada com equações algé-

13 De acordo com Rabuel, as questões que requerem explicações das ovais são as seguintes: (1) A reflexão e a refração da luz; (2) a descrição de quatro espécies de ovais; (3) suas propriedades em relação à reflexão e à refração da luz e a demonstração dessas propriedades; (4) quais as propriedades do círculo, da parábola, da elipse e da hipérbole que têm relação com a reflexão e a refração da luz; (5) a figura que é necessário fornecer aos materiais a fim de que eles reúnam em um ponto dado os raios que vêm de um outro ponto dado (cf. Rabuel, 173o, p. 337). 
bricas mediante a proporcionalidade de pontos regulares, ou por cordas, como Descartes fizera em $A$ dióptrica para o caso da hipérbole e da elipse. Em outras palavras, derivando a equação do lugar nas indeterminadas $x$ e $y$ e escolhendo valores arbitrários para $y$, encontra-se o lugar geométrico para as raízes em $x$. A exposição das propriedades ópticas dos ovais exige um método algébrico para a determinação da tangente a um ponto de uma curva. Assim, a estratégia seguida por Descartes consiste em primeiro encontrar a normal a uma curva em um determinado ponto: a tangente procurada será, portanto, a ortogonal a esta naquele ponto.

Descartes propõe que a tangente a uma curva geométrica em um ponto possa ser considerada a posição limite de uma secante da curva; secante que, por sua vez, pode ser vista como a corda da circunferência que intercepta a curva em dois pontos distintos. Quando a reta é tangente, também o círculo é tangente à curva no mesmo ponto, e as duas intersecções com a curva são reunidas em um único ponto: viabilizando-se a aquisição da forma anaclástica.

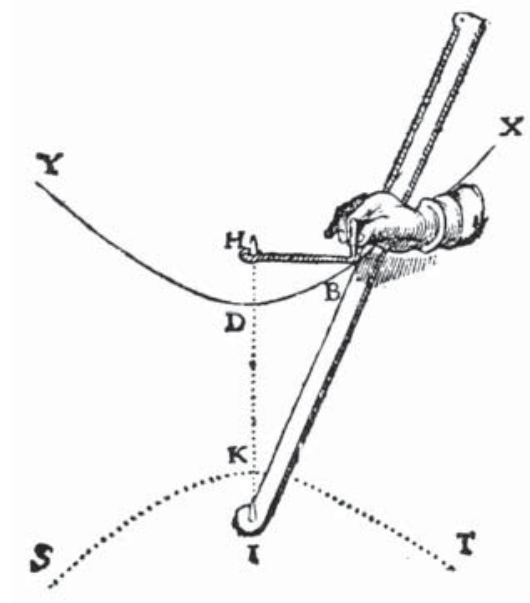

Figura 16 (AT, 6, p. 176).

No Discurso viıI de $A$ dióptrica, Descartes explica como a inteligibilidade matemática das ovais serve para realizar as construções por cordas. Para obter uma hipérbole, deve-se girar uma régua ao redor de I. Quando a régua gira ao redor de I com B fixo na régua e $\mathrm{HB}$ tenso, B descreve uma hipérbole cujos focos são I e H (cf. AT, 6, 176-8).

Constata-se, assim, que as ovais de Descartes foram encontradas quando se procurou a solução do problema da óptica que tem a finalidade de determinar a superfície de separação dos meios transparentes de densidades diferentes, para que os raios emitidos por um ponto luminoso situado em um dos meios convirjam a um ponto fixo do outro meio. E é a partir desse aspecto que se viabiliza a determinação da forma da anaclástica.

\section{0 legado de $A$ dióptrica de Descartes:} REPERGUSSÕES E POLÊMIGAS NOS SÉGULOS XVII E XVIII

É exposto, neste momento, o modo como os sucessores de Descartes rejeitam e, por vezes, ratificam determinados aspectos de $A$ dióptrica. É explicitado também o modo como Descartes opõe-se às demonstrações ópticas de Pierre Fermat (1601-1665) a partir da concepção da matemática universal. Ressalte-se que, dentre os sucessores, destacam-se principalmente o próprio Fermat e Christian Huygens (1629-1695). 
Primeiramente, são expostas as divergências que existem entre Descartes e os integrantes do círculo de Mersenne, sobretudo, quando se trata de Fermat. Tais divergências assinalam a relevância do método de Descartes frente aos cálculos e às descrições científicas realizadas por Fermat e seus defensores.

Descartes não entende, a respeito da objeção feita por Fermat a $A$ dióptrica, como alguém pode refutar uma demonstração tão sólida, utilizando-se de argumentos tão frágeis (cf. AT, 2, p. 263-4). Diante disso, Descartes reclama, em uma carta a Mersenne, referente à demonstração que apresentou em $A$ dióptrica:

Por último, a saber, que se a bola que está no ponto B é impelida por duas forças iguais, sendo que uma leva de $\mathrm{B}$ em direção a $\mathrm{D}$, e a outra de $\mathrm{B}$ em direção a $\mathrm{G}$, ela deve mover-se em direção a I, de modo que o ângulo GBI seja igual a IBD; e que, igualmente, sendo impelida de B em direção a N e em direção a I, ela deve ir em direção a L, que divide o ângulo NBI em duas partes iguais; essas premissas são verdadeiras, mas elas nada contêm que diga respeito às refrações, as quais não são causadas por duas forças iguais como as que projetam a bola, mas sim pelo encontro oblíquo com a superfície em que se fazem; e, assim, eu não sei por meio de que lógica ele pretende inferir disso que o que eu escrevi não é verdadeiro (AT, 2, p. 264).
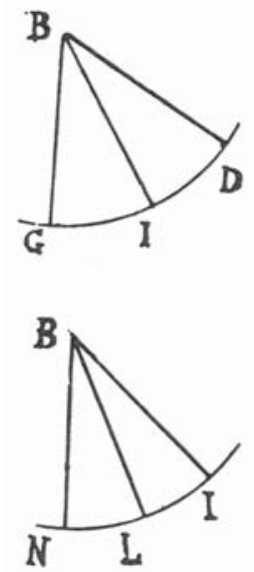

Figura 18 (AT, 2, p. 264).

\section{Esse argumento de Descartes indica que Fermat não}

teria entendido a diferença entre o cálculo que prescreve a descoberta da lei dos senos e a efetiva demonstração da refração da luz. Tal diferenciação requeria o pleno entendimento dos modus operantis do método de Descartes. ${ }^{14}$ Para examinar o modus operantis do método de Descartes, é necessário expor a crítica que Descartes realiza ao cálculo dos máximos e mínimos de Fermat. Deve-se assinalar que esses cálculos são referentes ao modo pelo qual Fermat demonstra o movimento da luz. ${ }^{\mathbf{1 5}}$

14 Uma outra questão que gera conflito na interpretação de $A$ dióptrica de Descartes por parte de Fermat é a plena compreensão do que seja a instantaneidade. Segundo Paty, é preciso reter “a ideia de instantaneidade, que está no centro da ideia de movimento em Descartes, mesmo que, por outro lado, Descartes não se preocupe expressamente em exprimir as leis do movimento em função do tempo". Continua Paty, em outra passagem: "Descartes enuncia e frisa [...] a equivalência de todos os instantes, sendo, pois, a luz que lhe inspira essa ideia. Ele afirma que não existe propriedade do tempo, compreendendo-o no sentido de que todas as partes da luz em todos os instantes sucessivos são dependentes dos precedentes, e essa dependência é constante de um instante ao outro, o que na nossa compreensão atual parece uma espécie de prefiguração da lei diferencial" (cf. Paty, 1998, p. 9-57).

15 Acrescenta-se que Descartes relata a Mersenne, em uma carta datada de 29 de junho de 1638, os equívocos dos de maximis da óptica de Pierre Fermat (cf. AT, 2, 174,-96). 
Cabe aqui esclarecer que, ao procurar determinar os máximos e os mínimos de uma curva, Fermat notou que, em certos pontos em que a curva tem os máximos e os mínimos, a tangente seria paralela ao eixo horizontal. Assim, Fermat transformou o problema de conhecer os máximos e mínimos em um outro: localizar os pontos em que a tangente à curva é paralela ao eixo horizontal. Este processo conduziu-o à noção de derivada: para encontrar a tangente, utilizou a posição limite de uma secante, desde que os pontos de intersecção com a curva tendem a aproximar-se. Em 1639, divulga um novo método para determinação de tangentes, estudo que levaria aos máximos e mínimos. Formula também o princípio do tempo mínimo no campo da óptica.

Em uma carta datada em 1 março de 1638 enviada a Mydorge, Descartes estabelece as questões que irá tratar para se defender das objeções postas por Fermat. Encontra-se, desde então, o modus operantis do método de Descartes. Na primeira questão, Descartes examina a refutação que Fermat faz a $A$ dióptrica, sendo a Mersenne a quem ele objetara. Na segunda, Descartes expõe a defesa dos argumentos da Dióptri$c a$. Na terceira, Descartes examina a obra latina maximis \& minimis de Fermat. Na quarta, Descartes realiza objeções à obra de Fermat. Na quinta, são expostos os argumentos dos defensores de Fermat. Na sexta, Descartes expõe uma resposta aos defensores de Fermat. Na sétima, é exposta uma réplica de Fermat à primeira resposta de Descartes no tocante a $A$ dióptrica (cf. AT, 2, p. 16-7).

A crítica ao cálculo dos máximos e mínimos de Fermat, enviada por Descartes a Mersenne, é estabelecida em duas partes distintas. Essa crítica é relatada em uma carta datada de 11 de outubro de $1638 .{ }^{16}$

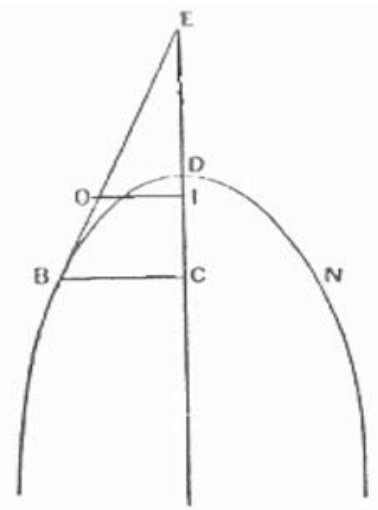

Figura 19 (Milhaud, 1921, p. 150).

Na primeira parte da crítica, Descartes examina a aplicação das tangentes de Fermat da seguinte maneira: seja a parábola BDN; de modo que a tangente seja construída através de um traço do ponto $\mathrm{D}$ até ao ponto B. Nessa medida, Descartes constata que BE encontra o eixo em $\mathrm{E}$. $\mathrm{O}$ ponto $\mathrm{O}$ dessa tangente é exterior à parábola. BC e OI são as coordenadas dos pontos $\mathrm{B}$ e $\mathrm{O}$; portanto, tem-se: $\mathrm{CD} / \mathrm{DI}$ maior do que o segmento de reta $B C^{2} / O I^{2}$. Através dos triângulos semelhantes, Descartes constata que $\mathrm{CD} / \mathrm{DI}$ é maior do que o segmento de reta $C E^{2} / I E$. Designando as dimensões $\mathrm{CD}$ e $\mathrm{CE}$ por $\mathrm{D}$ e A, obtém-se: $C I$ = E. Logo:

16 A crítica de Descartes diz respeito à incompreensão dos seus interlocutores em relação ao método analítico. Neste enfoque, seguem-se os passos de Milhaud (cf. Milhaud, 1921, p. 150-5). 


$$
D / D-E>A^{2} /(A-E)^{2} \text { ou } D\left(A-E^{2}\right)>A^{2}(D-E) .
$$

Então, são igualados os dois membros das desigualdades. Por isso, Descartes suprime o termo comum D . $\mathrm{A}^{2}$, donde é necessário dividir os termos restantes por E; e, assim, obtém-se: $D . E-2 A . D+A^{2}=0$ (ver figura 19). Pode-se fazer o seguinte: $E=0$ e $A={ }_{2} D$. Isso irá fixar o valor da subjacente A. A partir desse exame, Descartes deseja mostrar que o método geral dos máximos e mínimos, quando diretamente aplicado ao problema da tangente da parábola, não auxilia em nada a encontrar a tangente; portanto, chega ao contrário do que afirmava Fermat. Retomando a figura e as anotações deste, Descartes procura a distância máxima que pode haver do ponto E até a parábola cuja regra é incorreta para Descartes (cf. Milhaud, 1921, p. 150-1). Então, deve-se partir de onde se tem o segmento de reta ao quadrado de $B E=A^{2}+B^{2}$, pois quando EC torna-se A + E, consequentemente DC torna-se D + E. E como o lado reto (latus rectum) da parábola é $\mathrm{B}^{2} / \mathrm{D}$, por conseguinte $\mathrm{B}^{2}$ torna-se igual a: $(D+E)$. $B^{2} / D$. Logo, $\mathrm{A}^{2}$ tornase $(A+E)^{2}$. Encontra-se por esse segmento de reta ao quadrado de BE, a expressão:

$$
(A+E)^{2}+B^{2} D+B^{2} E / D
$$

No caso em que é igualada à primeira, obtém-se:

$$
A^{2}+B^{2}=A^{2}+2 A E+E^{2}+B^{2}+B^{2} E / D \text { ou } 2 A E+E^{2}+B^{2} E / D=0 .
$$

Ou, enfim, depois da divisão por $E, 2 A+B^{2} / D=0$ (cf. Milhaud, 1921, p. 151).

Na segunda parte da crítica, Descartes examina o raciocínio de Fermat através da construção da tangente da parábola; e, em seguida, explica que esse raciocínio apenas é válido para a construção da parábola. Ou seja, inútil para a construção analítica da elipse e da hipérbole. Esse fato revela que o método universal - mathesis universalis não é admitido nos raciocínios matemáticos de Fermat.

De acordo com Descartes, a relação das abscissas dos pontos B e O deve ser superior ao quadrado das ordenadas. Por isso, não é possível determinar a tangente nas outras secções do cone. Então, torna-se necessário reconhecer que a primeira vertente dessa explicação não é favorável a Descartes. Nessa perspectiva, Milhaud questiona-se:

Por meio de que aberração Descartes pode entender isso, isto é, se levarmos em consideração apenas seus últimos comentários: que a relação entre o quadrado das ordenadas e das abscissas, que caracterizam a parábola, constituem a desigualdade que serve de ponto de partida para a construção de Fermat (Milhaud, 1921, p. 152). 
Poderia ser, por meio do raciocínio do geômetra de Toulouse, a relação geral a ser utilizada em todos os casos e, portanto, sem importar a curva realizada? Segue Milhaud: "Quanto à primeira carta, perdida, mas cujo conteúdo é presumido pelo que Descartes diz a Mydorges (em 1 de março de 1638): que Etienne Pascal e Roberval teriam insistido nesse mesmo erro".

De acordo com Milhaud, dividindo as páginas em duas colunas, Descartes reproduz, em um lado, a demonstração de Fermat para a tangente da parábola e, no outro lado, explica a mesma tangente da parábola descrita algebricamente, isto é, para o mesmo caso da construção da elipse e da hipérbole, de maneira a conduzir o cálculo ao absurdo. Essa explicação - que o cálculo é conduzido ao absurdo - é descrita por Roberval (cf. Milhaud, 1921, p. 152).

Quanto à primeira parte da crítica, Descartes solicita explicações sobre a possibilidade de Fermat definir a tangente em B, isto é, não pelo fato de que EB fosse um comprimento máximo ou mínimo, mas pelo fato de que sobre EB, o ponto B é aquele que a quantidade algébrica passaria por um mínimo (cf. Milhaud, 1921, p. 152). É o que dirão pela segunda vez os defensores de Fermat. Isso ocorre depois da resposta de Descartes a Mydorge. Nesse contexto, Roberval retoma os mesmos argumentos apresentados pela primeira vez por Pascal (em meados de abril de 1638). Todavia, segundo Milhaud, tais argumentos estariam equivocados. Esses matemáticos têm razão em não aceitar que a tangente B na parábola possa ser determinada pela procura de uma corda de comprimento máximo ou mínimo EB, cuja explicação é fornecida por Descartes através do cálculo que demonstra tal inutilidade (cf. Milhaud, 1921, p. 152). Milhaud constata que nem os matemáticos, nem Desargues, nem o próprio Descartes, parecem perceber a verdadeira razão pela qual a aplicação que Descartes faz ao método de Fermat leva ao absurdo, pois, invocar simplesmente, como faz Roberval, que as cordas levadas de $\mathrm{E}$ até a parábola cresçam indefinidamente, para rejeitar o máximo ou mínimo EB, não é, em absoluto, mais exato do que a hipótese, admitida sem discussão por Descartes, que prescreve que a tangente $\mathrm{EB}$ é necessariamente a maior das retas que vão de $\mathrm{E}$ até a parábola. Desse modo, quando Desargues concebe que, a propósito das cordas passando por $\mathrm{B}$, pode-se falar de vários modos de máximos ou mínimos, dará razão a Descartes, sem perceber que este afirma que o método de Fermat é incompreensível, quando é necessário construir a tangente. Todavia, Descartes não explica com detalhes essa descrição matemática; mas em todo caso, é estranho o resultado obtido por Descartes, a saber, que aplicando rigorosamente o método de maximis et minimis na procura do máximo e do mínimo de EB, quando se deseja mostrar a correção do raciocínio que o conduziu, chega-se ao absurdo (cf. Milhaud, 1921, p. 153).

Contudo, segundo Milhaud, Descartes não percebe que, em vez de corrigir o método de Fermat, apenas corrige o seu próprio erro. Isso ocorre porque Descartes 
empreende um cálculo para uma matemática não desejada por ele. Ora, mas de que trata esse raciocínio matemático de Descartes? Segundo Milhaud (cf. 1921, p. 153), trata, manifestamente, de encontrar as retas máximas e mínimas partindo do ponto E até a parábola (ver figura 20). Isso porque, se EB fosse uma das normais, saber-se-ia de maneira evidente que a sub-normal $\mathrm{CE}$ é igual ao parâmetro do valor constante da razão $\mathrm{BC}^{2} / 2 \mathrm{DC}$. Nas anotações de Fermat e de Descartes, o ponto A é igual a B2/2D (cf. Milhaud, 1921, p. 153). Esse resultado absurdo do cálculo de Descartes depende da posição do ponto E em relação ao ponto D. Destarte, é necessário colocar o ponto B em relação ao eixo, para obter uma segunda solução. Se enfim notar-se que a convergência simultânea das quantidades B e D exclui a terceira solução ED, constata-se que a aplicação realizada por

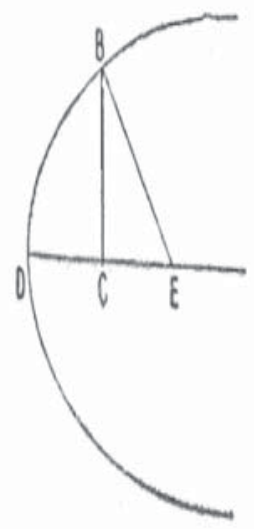

Figura 20 (Milhaud, 1921, p. 153). Descartes do método de Fermat, relativo à construção das normais através de linhas máximas traçadas a partir de E, procede corretamente. Com isso, segundo Milhaud, Descartes explicava o valor do método, enquanto acreditava demonstrar sua inexatidão. E o estranho é que Etienne Pascal e Roberval não tenham percebido o objetivo do método cartesiano (cf. Milhaud, 1921, p. 153).

Torna-se necessário examinar a correção enviada em correspondência por Descartes a Hardy (cf. AT, 2, p. 172), pois, nesse contexto, Descartes afirma que o ponto Eponto principal para a resolução da tangente - é descoberto analiticamente. Em uma carta datada em junho de 1638, Descartes faz o seguinte comentário: "como se deve modificar o método de Fermat para conseguir definitivamente a construção da tangente" (Milhaud, 1921, p. 154). Descartes toma como exemplo uma parábola cúbica, mas esse raciocínio, segundo Descartes, pode igualmente ser realizado sobre uma parábola simples. A mudança determinante é que a progressão $\mathrm{E}$ ou $\mathrm{CF}$ seja aquela que corresponde ao segundo ponto de encontro de EB com a parábola (ver figura 21). Nesse enfoque, Descartes toma duas incógnitas em vez de uma, a saber, A e E, e coloca provisoriamente uma relação arbitrária entre as ordenadas $\mathrm{BC}$ e DF, de forma a escrever tantas equações quanto incógnitas, constituindo-se o sistema da coordenada

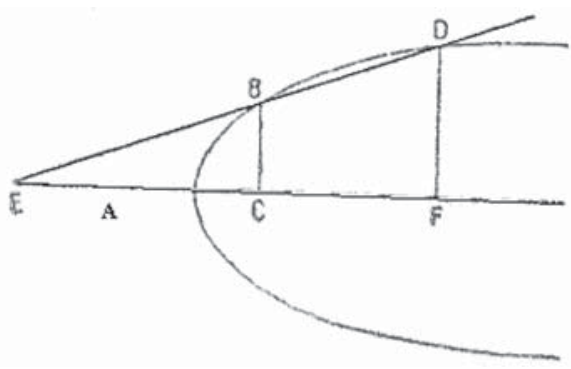

Figura 21 (Milhaud, 1921, p. 154). analítica que propõe $\mathrm{E}=0$. Como os pontos $\mathrm{E}, \mathrm{B}$ e D estão em linha reta, admite-se que colocando E = o passa-se da secante para a tangente (cf. Milhaud, 1921, p. 154). 
Todavia, por que Descartes não admitira que o problema era outro e que o método verdadeiro não era mais o de Fermat? (cf. Milhaud, 1921, p. 155). Para respaldar essa mencionada questão, deve-se admitir que a reta EB não é a maior linha traçada de $\mathrm{E}$ até a curva, mas sim o limite de uma secante cujos dois pontos de encontro com a curva tendem a combinar-se. Com isso, Descartes acreditava corrigir o método matemático de Fermat, mas, na realidade, deixava de basear-se em um postulado que ele mesmo havia hipoteticamente enunciado; e, assim, resolveu o problema por outro caminho, de modo absolutamente correto, mas completamente diferente da solução apresentada por Fermat. Isso porque o que legitima o raciocínio de Descartes não é meramente o resultado da construção da tangente, mas a natureza plenamente inteligível da parábola (cf. Milhaud, 1921, p. 155). ${ }^{17}$ Essa resolução é oriunda do modo como Descartes utiliza a matemática a favor da elaboração do método universal.

Os debates a respeito dos raciocínios matemáticos que sustentam $A$ dióptrica de 1637 - e que entram em conflito com os cálculos e o modo como Fermat interpreta a descoberta da lei de refração cartesiana - foram publicados após a morte de Descartes. Clerselier insere, no terceiro tomo da correspondência do filósofo, doze cartas entre o próprio Clerselier, Fermat, Rohault e La Chambre. Eis, ao lado, a ordem das cartas (ver figura 22).

Sabe-se que Christian Huygens se manteve fiel a diversos aspectos do método científico de Descartes. Entretanto, Huygens percebeu algumas falhas da física cartesiana e se propôs a corrigi-las. Segundo Kobayashi (1996, p. 147-8), a vertente cartesiana em Huygens é manifesta, sobretudo, na concepção de gravidade que ele estabelece em seu "Discurso da causa da gravidade", publicado no Tratado da luz. Esse aspecto é relevante, porque contrapõe-se à posição em vigor no século xvIII, a saber, aquela de Newton, que pressupunha a ação a distância.

No Tratado da luz, Huygens estabelece dois aspectos determinantes para tratar o movimento da luz, a saber, que a luz é "uma matéria fluida que consiste em partes muito pequenas e que é diversamente agitada em todos os sentidos com muita rapidez" (Huygens, 1967, p. 135) e "partes bastantes maiores ou corpos feitos de conjuntos de

\footnotetext{
17 "Por um lado, existe a incompreensão própria de Descartes; por outro, ela é acompanhada pela do público e, finalmente, mais uma vez constata-se que existiam demonstrações truncadas, inspiradas, sem dúvida, pelas razões que levaram Descartes a mutilar a exposição de $A$ dioptrique e a esconder as diligências que o tinham levado à lei de refração. Mais tarde, $A$ geometria conheceu a sua verdadeira glória. Ao mesmo tempo, descobriu-se, pela análise dos documentos provenientes de Fermat, que este não era estranho à geometria analítica" (Philonenko, 1996, p. 70-1). Diante disso, persuadimo-nos com a leitura equivocada de Philonenko, ou seja, as interpretações, que o comentador infere a respeito do objetivo de Descartes, não condizem fielmente com as pretensões de nosso autor. E inclusive Philonenko não explicita os possíveis equívocos de física que Descartes houvera cometido, ou em outras palavras: qual foi problema da lei de refração e quais são os pressupostos truncados? E, afinal, quais são as discordâncias entre Descartes e Fermat? Os comentários de Philonenko carecem de tais explicações.
} 
Demonstração do movimento da luz no ensaio de óptica de Descartes

I. Fermat à Clerselier, Toulouse, 3 mars 1658

II. Fermat à Clerselier, Toulouse, to mars i658

$$
\text { (Lettre 43, p. 198-199). }
$$

IiI. Clerselier à Fermat, Paris, i 5 mai i 658

$$
\text { (Lettre H+, p. 199-205). }
$$

(Lettre 45, p. $206-21+$ ).

IV. Rohault à Clerselier pour Fegmat, meme date

V. Fermat à Clerselier, 2 juin 1658

$$
\text { (Lettre } \$ 6, p .215-221) \text {. }
$$

Vi. Fermat à Clerselier, 16 juin 1658

$$
\text { (Lettre }+7, \text { p. } 221-226) \text {. }
$$

ViI. Clerselier à Fermat, Paris, $2 \mathrm{I}$ aoù 1658

$$
\text { (Lettre }+9, \text { p. } 231-2+6 \text {. }
$$

VIII. Fermat à La Chambre, Toulouse, aoùt 1657

(Lettre $50, p .2+6-252)$.

IX. Fermat à La Chambre, Toulouse, $1^{\text {er }}$ janvier 1662

$$
\text { (Lettre } 5 I, p .252-276) \text {. }
$$

X. Clerselier à Fermat, Paris, 6 mai 1062

$$
\text { (Lettre 5.2, p. } 276-284 \text { ). }
$$

XI. Clerselier à Fermat, Paris, i 3 mai 1662

$$
\text { (Clers., lettre 53, p. 28+-295). }
$$

XiI. Fermat à Clerselier, Toulouse, 12 (lire 21 ?) mai 1662

$$
\text { (Clers., lettre } 54, \text { p. 2!)6-29\%). }
$$

Figura 22 (AT, 2, p. 23).

pequenas partes aglomeradas que não seguem o movimento rápido da referida matéria" (p. 137). Ao relatar os dois aspectos a respeito do movimento da luz, Huygens explica a gravidade à maneira de Descartes: pela pressão que a matéria fluida exerce sobre os corpos maiores impelindo-os em direção ao centro da Terra.

No que se refere à natureza da luz, Huygens apresenta também uma ideia muito semelhante à de Descartes, a saber, que a natureza da luz consiste na propagação da ação, em oposição, por exemplo, àquela explicação que previa o transporte de corpos. Recordemos que, para Descartes, a natureza da luz é transcrita pelas leis do movimento mecânico. Nesse sentido, Huygens mantém-se próximo a Descartes, quando estabelece algumas características do movimento da luz, a saber, (1) que a luz se estende ao redor de todos os lados dos corpos a que denominamos luminosos, e que diversos raios luminosos, vindos do mesmo ponto, podem ir a diversos pontos e (2) os raios de luz, vindos de diversos pontos e dirigindo-se para vários pontos, podem passar por um mesmo ponto sem se perturbarem uns aos outros (cf. Huygens, 1967, p. 19). Huygens acredita também que o movimento da matéria está relacionado com o fato de a matéria 
extremamente sutil agitar os corpos luminosos com grande rapidez; isso porque "fazem colidir contra as partículas do éter que os rodeiam” (Huygens, 1967, p. 13). Além disso, Huygens ressalta: "este movimento exercido sobre a matéria é sucessivo e, portanto, é uma propagação das ondas esféricas" (Huygens, 1967, p. 13). Baseando-se em tais considerações, Huygens desejou elaborar uma explicação que permitisse ampliar o uso da demonstração do movimento da luz, estabelecida por Descartes em $A$ dióptrica.

Embora aderindo à explicação do movimento da luz de Descartes, Huygens elimina determinadas noções que caracterizam a física cartesiana, entre elas a concepção de massa (cf. Kobayashi, 1996, p. 153). Descartes pressupõe que a massa deve estar relacionada com a superfície do corpo e que a gravidade dos corpos nem sempre possui a mesma relação com a sua quantidade de matéria. Huygens, porém, não adere a essa concepção cartesiana. De igual modo, quando examina os problemas concretos dos fenômenos terrestres, não adere ao holismo cartesiano que prescreve que se deve sempre relacionar os problemas dinâmicos (cf. Kobayashi, 1996, p. 153-4). Desse modo, Huygens refuta a concepção cartesiana de massa, o que torna possível calcular a quantidade de matéria (massa) de um corpo através do seu peso e, portanto, concentrar a sua massa no seu centro de gravidade, sem qualquer relação com a sua superfície.

\section{Considerações finais}

O texto de $A$ dióptrica não pode ser entendido separadamente dos pressupostos metódicos desenvolvidos a partir dos raciocínios matemáticos de Descartes. Deve-se acrescentar ainda que a expressão "óptica geométrica” é utilizada para designar-se a óptica cartesiana, uma vez que elementos fundamentais de $A$ dióptrica, tais como a concepção corpuscular da luz e a ideia de que sua propagação ocorre instantaneamente e em linha reta, continuam exercendo papéis determinantes na óptica pós-cartesiana. Os pressupostos metódicos desenvolvidos a partir dos raciocínios matemáticos de Descartes são contemplados pela designação da mathesis universalis: modelo que, quando aplicado ao conhecimento dos corpos extensos, permite identificar, na matéria, relações de ordem e medida e delas deduzir verdades necessárias. A mathesis universalis, portanto, segue os preceitos lógicos descritos por Descartes no Discurso do método. Diante disso, expõe-se brevemente, a seguir, o modo como Descartes poderia metodicamente descobrir a lei de incidência e refração, para chegar à demonstração do movimento da luz em $A$ dióptrica.

Os preceitos lógicos de Descartes, por serem "a longa cadeia de razões na qual os geômetras se firmam" (AT, 6, p. 19) possibilitam a viabilização instrumental da mathesis universalis, por meio de uma metodologia experimental. Então, seguindo os passos dos 
preceitos lógicos de Descartes, constata-se que: (1) o primeiro preceito lógico postula, por meio da longa cadeia de intuições, a evidência da descoberta da lei dos senos, a saber, sen i/sen r; (2) o segundo preceito lógico postula que é necessário efetuar a redução dos objetos compostos, para, em seguida, compô-los mediante a construção experimental; (3) o terceiro preceito lógico postula que é necessário orientar, por ordem, os pensamentos, a saber, partindo dos objetos mais simples e mais fáceis de conhecer (como a relação: sen $i / \operatorname{sen} r$ ) até a representação dos mais compostos (demonstração geométrica do movimento da luz), por meio da longa cadeia de deduções; (4) e o quarto preceito lógico postula que é necessário realizar enumerações completas e revisões gerais, para que não haja a mínima possibilidade de omitir questões que versem sobre o movimento da luz (cf. AT, 6, p. 18-9).

Por fim, $A$ dióptrica é uma obra composta de diversos experimentos científicos, os quais pretendem, sobretudo, estabelecer a lei incidência/refração mediante a demonstração do movimento da luz. Nessa empreitada, Descartes norteia-se pelo método do Discurso do método, que, não devemos esquecer, é a introdução do texto de A dióptrica, cuja tradução publicamos aqui.@

José Portugal dos Santos Ramos Doutorando do Programa de Pós-Graduação em Filosofia, Instituto de Filosofia e Ciências Humanas, Universidade Estadual de Campinas, Brasil. domluso@gmail.com

\section{REFERÊNGIAS BIBLIOGRÁFIGAS}

Adam, C. \& Tannery, P. (Ed.). Oeuvres de Descartes. Paris: Vrin, 1996. 11 v. (AT)

Costabel, P. Démarches originales de Descartes savant. Paris: Vrin, 1982.

Сottingham J. Dicionário Descartes. Tradução H. Martins. Rio de Janeiro: Jorge Zahar, 1993.

Garber, D. Corps cartésiens: Descartes et la philosophie dans les sciences. Paris: PUF, 2004.

Gaukroger, S. Descartes: uma biografia intelectual. Rio de Janeiro: Editora da UERJ, 2002.

Gilson, É. Discours de la méthode. Texte et commentaire. Paris: Vrin, 1987.

Huygens, C. Traité da la lumière. Bruxelles: Culture et Civilisantion, 1967.

Jullien, V. Descartes, la "Géométrie" de 1637. Paris: PUF, 1996.

Ковауазні, M. A filosofia natural de Descartes. Lisboa: Instituto Piaget, 1996.

Koyré, A. Considerações sobre Descartes. Lisboa: Presença, 1992.

Korteweg, D. J. Descartes et les manuscrits de Snellius. Revue de Metaphysique et de Morale, 4, 4, p. 4.89$501,1986$.

Mersenne, M. La vérité des sciences. Paris: [s./n.], 1625.

Milhaud, G. Descartes savant. Paris: Félix Alcan, 1921. 
Paty, M. Mathesis universalis e inteligibilidade em Descartes. Cadernos de História e Filosofia da Ciência, 8,1, p. 9-57, 1998.

Philonenko, A. Reler Descartes. Tradução F. Oliveira. Lisboa: Instituto Piaget, 1996.

Rabuel, C. Commentaires sur la “Géometrie” de monsieur Descartes. Lyon: Mercellin Duplain, 1730.

Rodis-Lewis, G. Descartes: a biografia. Tradução F. Oliveira. Lisboa: Instituto Piaget, 1996.

Schuster, J. Descartes and the scientific revolution, 1618-1634. Ph.D.Thesis. Princeton University, 1977. 2 v.

SheA, W. La science de Descartes. Laval Théologique et Philosophique, 53, 3, p. $5^{31-49}, 1997$.

Weber, J. P. La méthode de Descartes d'après les “Regulae". Archives de Philosophie, 35, p. 51-60, 1972.

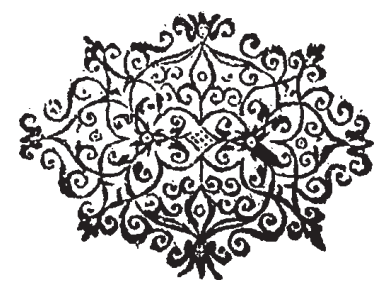

